\title{
Arbor
}

\section{La pintura vista por un pintor joven}

Pedro Fuentes Pozo

Arbor CLXV, 649 (Enero 2000), 83-90 pp.

El pintor se define a lo largo del tiempo como un artista en mutación influenciado por la sociedad de su momento y por su propio mundo interior. Esto ha contribuido a la creación de distintos estilos pictóricos y a una evolución que conlleva la despreocupación por el aspecto formal en aras de una introspección al mundo interior. En el cambio constante se refleja la búsqueda del artista que valida la intemporalidad del arte. Así, el verdadero artista sobrevive al aplauso o rechazo de la crítica, convirtiéndose en un verdadero hombre renancentista preocupado por el hallazgo del conocimiento universal.

\section{El pintor como humanista}

Al enfrentarnos al análisis de la pintura del último milenio, observamos la gran variedad estilística, de tal magnitud, que se han escrito páginas y páginas y tanto tiempo empleado sobre la figura universal del pintor. El pintor como artista en maduración con el sentir de su entorno y la adversidad de su propia búsqueda. Una búsqueda que le lleva a las más altas cotas de su propia identidad, reflejando su mundo interior en cualquier soporte pictórico, temporal al mundo crítico e intemporal en su más íntima concepción.

Lo que imprime un carácter universal a la pintura del último milenio es la consideración de su propio artífice, el pintor, como un humanista. 
Resulta difícil hablar en estos días del pintor humanista sin que ello implique una vuelta al Renacimiento, pero es en este sentido donde se define con claridad el talante del pintor. Es en ese continuo renacer artístico donde reside la esencia de la pintura de estos siglos pasados.

El artista como ente aislado no existe y no puede existir por su necesidad intrínseca de comunicar al mundo exterior. Esa comunicación no solo se entiende en el marco social. Buen ejemplo de ello son Gauguin y Van Gogh que, evadiéndose del entorno estricto social, proyectaron su humanismo interior en la propia naturaleza.

Si remontamos nuestra mirada al pasado, a ese mundo renacentista donde se une la herencia de la Antigüedad clásica y de la Edad Media, el mismo Miguel Angel experimenta un proceso de cambio por su propia lucha interna y el mundo que le rodea y es en este sentido donde se establece el paralelismo con el artista de nuestro tiempo. En el genio renacentista se produce la tensión necesaria para abandonar sus inicios y el neoplatonismo del techo de la Capilla Sixtina. Ya no le sirven los modelos asimilados en el Alto Renacimiento. Su mundo exterior está en crisis. Se convulsiona junto con la sociedad que le rodea. Los cambios políticos y religiosos trastocan la idea de calma que posee el autor. Sus figuras se muestran tensas, con movimientos bruscos e irritables y trasmiten ese mundo en crisis, donde los valores se han caido dejando paso a una nueva etapa de reconversión pictórica.

Es en el «Juicio Final» donde el hombre del renacimiento pasa a ser algo menos o algo más en la esencia del mundo artístico, según se racionalice en un sentido u otro el manierismo pictórico que aconteció. Esa trasmutación valida al hombre del renacimiento porque reafirma su categoría «individuo-humano-artista». Según comenta el profesor De Bunes Ibarra, con el saqueo de Roma se producen cambios en la mentalidad de los hombres que viven en la Ciudad Eterna. El arte ya no se ve como un fenómeno autónomo, sino que se somete a la razón de estado.El pintor humanista refleja el efecto en su propia obra. Ya no siente igual y por lo tanto no muestra al exterior de la misma manera que lo venía haciendo.El Juicio Final deja de ser un monumento a la belleza y la juventud para convertirse en un reflejo de la angustia y la desesperación. En el cambio está el hombre y en el hombre se aloja el artista. Miguel Angel pintó de esta manera porque su mundo asi se lo requería.

Y ahora pensando en Leonardo de Vinci, quien mejor que él puede definir la pintura intemporal. La pintura eterna. Como él mismo decía, «la pintura es una poesía que se ve» y, probablemente, los más grandes 


\section{La pintura vista por un pintor joven}

FIGURA 1. "Il gludizio universale»

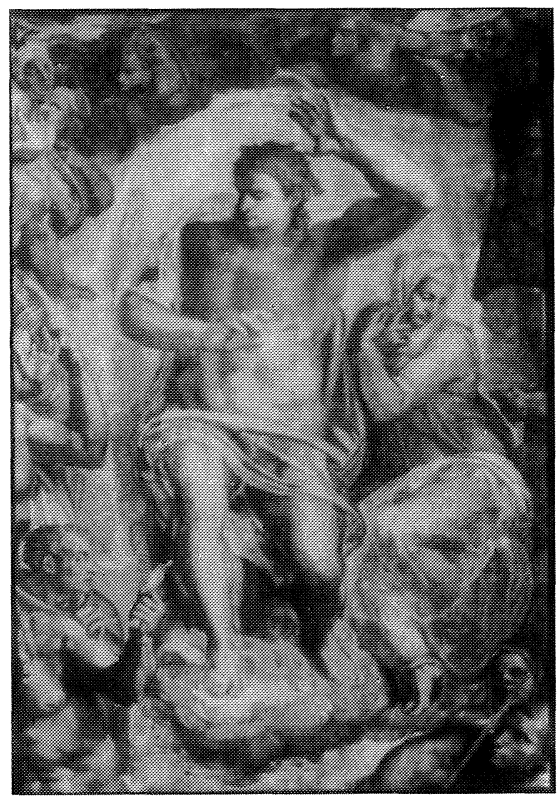

humanistas de la historia son los poetas. El lirismo, el amor y la muerte son la propia vida. La ciencia y la sociedad dignifican la vida y la decoran.

En este sentido Leonardo analiza el mundo que le rodea y, según sus propios consejos en su «Tratado de la pintura», nos dice como debemos observar las calles, el atardecer, los rostros de los hombres y las mujeres cuando hacen mal tiempo, la gracia y la dulzura que tienen... y entonces el aire es perfecto. "Mira la luz de la vela y contempla su belleza. Cierra los ojos de nuevo. Lo que ves ahora no existía antes y lo que existía ya no está ahora. Las sombras dan vida a los objetos y las formas se modifican continuamente con el juego del claroscuro que es finura y suavidad».

En la «Gioconda» el «sfumato» esconde al propio tiempo el misterio de la existencia y provoca a la imaginación para que tome parte en esa transformación de la realidad.

En estas ideas, hace quinientos años se encuentra el eje central que define a un pintor. La intemporalidad del arte se esboza poco a poco a lo largo de la historía del arte. La intención del artista en cada obra dota de valor a la misma. Su mensaje es el fondo y su técnica a través del color, composición y dibujo es la forma. La comunión 
de ambas dota al autor de la posibilidad de transmutar al unísono del mundo exterior.

Ese propio fenómeno cambiante del autor conforma las distintas escuelas pictóricas y asi podemos ver como en el Barroco español predomina la naturalidad y la humanidad. El sentido de búsqueda se traduce en el estudio de la luz y se ha perdido ese colosalismo heroico de epocas pasadas - escuelas italianas-.

Velázquez es el mejor exponente del pintor humanista. Su calidad de retratista en sus mejores obras llenas de humanidad, -bufones y sencillos personajes del pueblo-, anticipan su preocupación por ir más allá de lo que la sociedad de su tiempo le indicaba. Recordemos que uno de los motivos fundamentales por los que abandonó Sevilla era porque allí sólo se pintaba pintura religiosa y el genio buscaba algo más. Sus lienzos de «Los jardines de la Villa Medicis» se anticipan en más de doscientos años a la técnica del impresionismo. La intemporalidad del arte no está tanto en las obras en si mismas, sino en la forma de interpretar y de mirar la realidad del artista. Así, el impresionismo como escuela pictórica no tendría demasiado valor ya que genios como Velázquez y Goya a principios del siglo XIX ya eran impresionistas en sus telas. La escuela impresionista toma valor en el momento que refleja el sentir de su época a través de sus pintores y por lo tanto su aspecto de vanguardia queda legitimado.

En el caso de Velázquez, entre 1630 y 1645 realizó varias representaciones de bufones donde mostró el mismo interes con el que trataba a un noble. Sus personajes de fea y deforme figura son representados con humanidad, tratando de ocultar los defectos' en vez de recrearse en ellos.

En su obra «los borrachos» el autor toma los modelos de la realidad cotidiana. El pueblo de la calle, inspirado en auténticos bebedores de taberna, con sus rostros sonrosados dotados de un gran realismo. Asi deseaba plasmar el pintor sus sentimientos y mostrarlos a la sociedad de su tiempo.

No debemos olvidar que el verdadero enigma de la obra de arte es lo que el pintor espera encontrar en el espectador ante la observación de su obra. El Greco es una claro ejemplo a la hora de tratar sus temas con profunda fusión entre el mundo real y sus prolongaciones al más alla. Para él y su época el sentido religioso de la vida mediatizaba el mundo del arte. Es muy curioso observar como hasta 1908 no se reconoce el genio de su obra y personalidad y es entonces cuando su obra cobra una vigencia universal. Esa universalidad se la da el espectador que le brinda su comunión y entendimiento con lo que el 


\section{La pintura vista por un pintor joven}

FiguRA 2. «Los borrachos» Velázquez, Museo del Prado

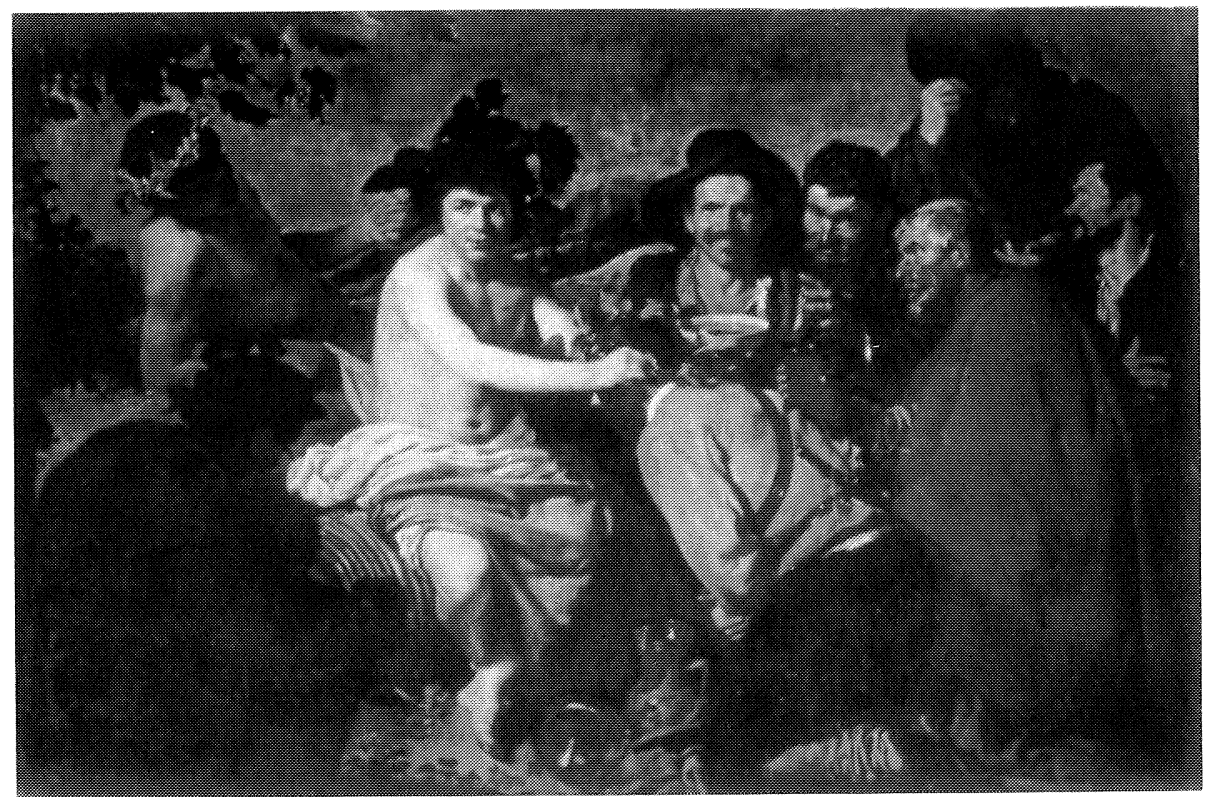

FIGURA 3. «Saturno devorando a su hijo» Goya, Museo del Prado

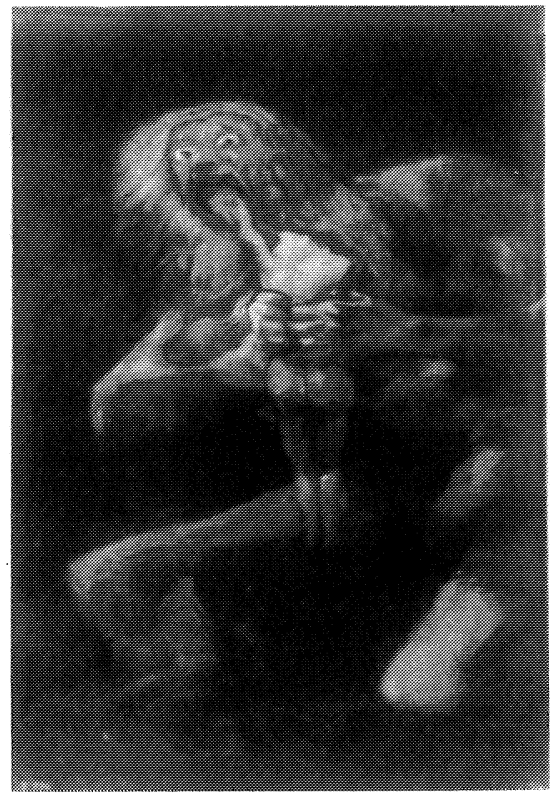


autor trasmite en sus lienzos. Esa espera de trescientos años para que su obra fuera reconocida, legitima la intemporalidad del arte ya que el humanismo pictórico se valida en cualquier momento que el espectador conexiona con el mundo interno y la proyección exterior del artista.

En la pintura holandesa observamos que la atmósfera de los interiores no da la impresión de indiferencia, sino de una presencia tenue. La unión del hombre con el recinto en el que vive. El impacto del autor con el exterior y sus propias emociones.

Rembrandt en sus años sombríos reflexiona sobre la vejez y el destino del hombre alcanza su mayor hondura y sus obras tintes más personales. Su «Ronda de noche» fue rechazada por su época ante su propia negación a halagar a los personajes que se representan. El humanismo de Rembrandt es evidente en un artista al que se ha definido como pintor del hombre. Tanto en él como en Velázquez hay un sentido humanista. Velázquez es poético y eleva la condición de los seres. Rembrandt refleja el dolor de la vida y el hombre.

En este sentido hay una unión con la obra final de Goya. Aparentemente el dolor y tragedia de destino del maestro aragonés tiene el mismo origen que en el holandés, pero en Goya se acentúa mucho más el dolor que le provoca la soledad generada a través del desastre social y no tanto del trágico destino personal. El humanismo de Goya está forjado desde el aspecto simbólico de sus cuadros de guerra y las pinturas negras, asi como sus desastres y aguafuertes. La intensidad expresiva de Goya nos muestra a un autor que se quiere salir del cuadro. Eso es lo que nos quiere trasmitir e intemporaliza su arte. Sus retratos tienen un carácter más efimero porque representan hechos que mueren en el tiempo. Las sensaciones son eternas y es ahí donde se puede establecer una ligazón con la obra posterior de Van Gogh.

En ambos casos se rompe el respeto a las leyes ópticas de pintar para asumir la responsabilidad de crear un mundo propio, donde el dolor interior y la crítica social son más importantes que la realidad visual. La intemporalidad nos muestra antecedentes a esta idea en El Bosco y Valdés Leal.

Desde el punto de vista técnico, Goya es un precursor del impresionismo y el propio Manet, profundizando en el carácter humanista del pintor, viene a España a estudiar la obra de Velázquez y Goya. En Goya podemos apreciar un grito que pretende cambiar la realidad que también conoce. Es el expresionismo vivaz que manifestará posteriormente el grupo Die Brucke de Dresde. 
Es importante indicar que hasta finales del siglo XIX se había representado al ser humano en la belleza y el dolor, el Renacimiento y el Barroco y solo Goya profundiza en los misterior del mundo interior.

Aunque generalmente los autores y académicos no lo mencionan, esta misma vivencia mueve a artistas como Van Gogh, Gauguin y el mismo Toulouse-Lautrec.

Para el primero su búsqueda de la utilidad humana le lleva a colorear intensamente con una luz cegadora, como símbolo de esa luz que lo envuelve todo y que ilumina al hombre al mismo tiempo que se dignifica con su trabajo.

Gauguin se inicia en el impresionismo con Pisarro pero trasciende más alla uniendo lo que ve con lo que imagina creando su universo propio con una intensidad poética excepcional.

Lautrec es más mundano en su relación con la sociedad de su tiempo. Necesita de ese ambiente social, el cual eleva sus carteles a las cotas del arte.

En ellos, el humanismo se refleja en su dolor nacido de la desesperación por la inaceptación de su mundo pictórico, cuyo carácter intemporal lo sublima haciéndolo eterno.

En general todos los pintores impresionistas se olvidaron del realismo imperante en la mitad del siglo XIX. Ya no había necesidad social de una pintura que se confundía con la fotografía. El autor pasa a buscar algo más que una técnica depurada. Necesita el soporte técnico para bailar en las sombras de su mundo interno y de los efectos de luz.

En una de las cartas que Van Gogh escribió, en abril de 1889, podemos destacar el carácter humanista del arte pictórico en el segundo milenio. Sin él saberlo, había definido en su lenguaje atormentado y poético el sentir de la pintura del siglo XX. La carta dice asi, .... «mi estado mental no sólo es sino que también ha sido abstracto, .... suponiendo que todo cambiara, el carácter, la educación, las circunstancias, entonces hubiera podido existir esto o aquello....».

En el siglo XX se produce una revolución morfológica, donde el artista traduce la concepción intelectual y social y se ve obligado a afrontar de forma diferente la realidad. La confusión de la primera guerra mundial, la reacción del fauvismo contra el impresionismo en pro del color, el nacimiento de un arte cerebral llamado cubismo, el dolor elevado a grito del expresionismo de Munch, el humanismo dinámico del futurismo a través de la belleza de la velocidad, el movimiento «Dadá», la ruptura con las convenciones sociales y la consciencia del surrealismo, la abstracción y vanguardias con un Kandinsky que pro- 
paga el elemento interior como determinante de la obra de arte, constatan el cambio como carácter esencial que define el aspecto humanista del arte de este siglo.

Según se ha definido, en Picasso se reúne el motor de todos los cambios, buscador incansable que muy probablemente nunca llegó a encontrar las líneas maestras de su propio arte. Su falta de respeto artístico consigo mismo hace de él un genio . En «las señoritas de Avinyó» irrumpe en el cubismo. Con su «Guernica» simboliza nuestra época con los miedos y mitos del hombre del siglo $\mathrm{XX}$, en su más pura expresión humanista.

Juan Gris, Miró, Dalí, Tapies .... definen movimientos plásticos cambiantes representándo el pensamiento y la sensibilidad de la sociedad de este siglo. Son la semilla para el fruto posterior de una generación de pintores que marcan una clara ruptura artística proclamando el arte no imitativo, representado en el grupo El Paso.

En los últimos siglos, el rasgo que define a la pintura es precisamente valorarla como arte. Como arte porque se engloba bajo el estilo general de los movimientos pictóricos y bajo el estílo individual del artista. El autor así se define por tener un estilo y conocer un lenguaje. Sin una de las dos la intemporalidad del arte no existe. Se puede tener un estilo y no poseer un lenguaje, en cuyo caso calificar de arte el hecho representa sus serias dudas. El artista tiene que poseer lo que el profesor R. Wollheim define como intención del pintor. Esta intención está en la cabeza del autor y determina que en una superficie dada se ha de ver una concreta representación.

Como expresaba B. Rusell, el artista genuino aspira a producir un trabajo que sea aplaudido, pero aún en el caso de que no se produzca, esto no alterará su estilo.

\section{Bibliografía}

Gombrich: «Historia del Arte. La Consecución de la Armonía». Ediciones Garriga S.A. Barcelona, Enero 1967.

Wollheim, Richard: La Pintura como Arte. Userdis S.A. Madrid, 1997.

Buonarroti, Miguel Angel: «Obras Escogidas». M.E. Editores. Madrid, 1997.

DA VincI, Leonardo: «Cuaderno de Notas». M.E. Editores. Madrid, 1993.

GaYa NuÑo, J.A.: "Arte del Siglo XIX". Ars Hispaniae. Editorial Plus Ultra, Madrid, 1966.

Bernard: «Vincent Van Gogh». Plaza Janes, Barcelona, 1996.

Rocamora, Carmen: "Ismos y Vanguardias del Siglo XX». Madrid, 1998. 